\title{
Qualidade física do solo e produtividade da cana-de-açúcar com uso da escarificação entre linhas de plantio
}

\author{
Marcos Aurélio Carolino de Sá(1), João de Deus Gomes dos Santos Junior(1), \\ Claudio Alberto Bento Franz ${ }^{(1)}$ e Thomaz Adolpho Rein ${ }^{(1)}$
}

(1)Embrapa Cerrados, BR 020, Km 18, Caixa Postal 08223, Planaltina, CEP 73310-970 Brasília, DF, Brasil. E-mail: marcos.sa@embrapa.br,
joao.jr@embrapa.br, claudio.franz@embrapa.br, thomaz.rein@embrapa.br

Resumo - O objetivo deste trabalho foi avaliar o efeito da escarificação entre linhas sobre o crescimento de raízes, a compactação do solo e a produtividade de soqueiras de cana-de-açúcar no Cerrado. O estudo foi conduzido por cinco anos, de 2009 a 2013, em Latossolo Vermelho acriférrico típico, de textura muito argilosa, no Município de Bom Jesus de Goiás, GO. Utilizou-se o delineamento de blocos ao acaso com dois tratamentos, com e sem escarificação, e quatro repetições. Foram avaliados: produtividade de colmos e de açúcar; densidade do solo; grau de compactação; intervalo hídrico ótimo; e massa de raízes. A escarificação do solo não afetou a produtividade de colmos ou a de açúcar, a massa específica de raízes e nem atributos físicos do solo. A densidade crítica do solo para o crescimento de raízes foi de $1,33 \mathrm{~g} \mathrm{~cm}^{-3}$, que corresponde a um grau de compactação de 87,9\%. A resistência do solo crítica à penetração de raízes é de 3,8 $\mathrm{MPa}$.

Termos para indexação: crescimento de raízes, densidade relativa, grau de compactação, intervalo hídrico ótimo, qualidade do solo, resistência à penetração.

\section{Soil physical quality and sugarcane yield with the use of inter-row chiseling}

\begin{abstract}
The objective of this work was to evaluate the effects of inter-row chiseling on root growth, soil compaction, and sugarcane ratoon yield in the Brazilian Cerrado. The study was conducted for five years, from 2009 to 2013, in a very clayey Rhodic Acrustox, in the municipality of Bom Jesus, in the state of Goiás, Brazil. A randomized complete block design was used comprising two treatments, with and without post-harvest interrow chiseling, and four replicates. Stalk and sugar yields, soil bulk density, degree of compaction, least limiting water range, and specific mass of roots were evaluated. Soil chiseling did not affect stalk or sugar yields, root density, nor soil physical attributes. Critical bulk density for root growth was $1.33 \mathrm{~g} \mathrm{~cm}^{-3}$, which corresponds to a degree of compaction of $87.9 \%$. Critical soil resistance to root penetration is $3.8 \mathrm{MPa}$.
\end{abstract}

Index terms: root growth, relative compaction, degree of compaction, least limiting water range, soil quality, penetration resistance.

\section{Introdução}

O advento da colheita mecanizada da cana-deaçúcar (Saccharum sp. L.) permitiu que a prática de queima dos canaviais fosse abolida. Ao mesmo tempo, essa prática aumentou o risco de compactação do solo e da degradação de sua estrutura pelo tráfego de colhedoras e transbordos, principalmente em condições de solo úmido (Otto et al., 2011; Souza et al., 2015). A escarificação das entrelinhas em soqueiras de cana-deaçúcar tem sido adotada para a deposição de fertilizantes e para amenizar a compactação do solo (Paulino et al., 2004; Bianchini et al., 2014). Entretanto, a eficiência dessa prática no manejo da compactação do solo e seus efeitos no sistema radicular tem sido motivo de controvérsia (Paulino et al., 2004). De acordo com
Smith et al. (2005), embora a cana-de-açúcar possua sistema radicular profundo, cerca de $50 \%$ das raízes concentram-se na camada de 0 a $20 \mathrm{~cm}$. Uma parte dessas raízes é renovada após a colheita.

Em recente revisão bibliográfica, Tim Chamen et al. (2015) constataram que intervenções mecânicas, como subsolagens ou escarificações, nem sempre são eficientes para mitigar a compactação do solo, pois normalmente têm efeito temporário, o que demanda repetições frequentes. Os autores alertam, ainda, sobre o fato de que o revolvimento do solo favorece a mineralização de matéria orgânica e o aumento da emissão de gases de efeito estufa.

A compactação do solo tem sido avaliada com base em alterações em sua densidade. Embora o manejo do 
solo tenha influência direta nesse atributo, ele também é influenciado por atributos do solo, como textura, mineralogia e conteúdo de matéria orgânica (Bernoux et al., 1998; Silva et al., 2010). Portanto, Håkansson \& Lipiec (2000) alertam que, isoladamente, a densidade do solo não é um atributo adequado para caracterizar a qualidade do solo. Assim, o conceito de grau de compactação do solo desperta interesse por ser de fácil entendimento e apresentar metodologia facilmente executável e de baixo custo (Silva et al., 2010). De acordo com a metodologia, os dados são normalizados em função da máxima densidade do solo, ou densidade de referência (Reichert et al., 2009), que também varia em função de atributos intrínsecos do solo, como textura e mineralogia (Reichert et al., 2009; Silva et al., 2010). No entanto, a normalização dos dados em relação à densidade de referência cancela a interferência daqueles atributos sobre as densidades, e cria o conceito de grau de compactação, ou densidade relativa, que permite a comparação entre solos com base apenas nos efeitos do manejo. Entretanto, informações sobre valores críticos de grau de compactação ainda são escassas, sobretudo para a cultura da cana-de-açúcar.

Nesse contexto, o método para determinação da densidade máxima do solo é de extrema importância. Håkansson \& Lipiec (2000) propuseram a aplicação de $200 \mathrm{kPa}$ de pressão, com consolidômetro, em amostras deformadas e com teor de água equivalente à tensão mátrica de $33 \mathrm{kPa}$. Entretanto, Suzuki et al. (2007) e Reichert et al. (2009) alertam que, embora este método seja adequado para solos frequentemente revolvidos, ele tem subestimado a densidade de referência em solos não revolvidos, nos quais seria mais adequada a aplicação de $1.600 \mathrm{kPa}$ de pressão em consolidômetro ou o ensaio de Proctor.

Outra variável utilizada em estudos de compactação do solo é a resistência à penetração, a qual, segundo Busscher (1990), varia em função do teor de água e da densidade do solo. De forma geral, tem-se adotado o valor de 2,0 MPa como limitante ao crescimento radicular e à produtividade da maioria das culturas (Silva et al., 2010), até mesmo da cana-de-açúcar (Otto et al., 2011). Entretanto, parece não haver consenso na literatura e é comum o uso de outros valores como críticos para esta cultura, como em Gonçalves et al. (2014), que utilizaram 2,5 MPa, e Cavalieri et al. (2011) e Souza et al. (2015), que consideraram como limitante 3,0 MPa, conforme trabalhos realizados com gramíneas forrageiras (Lipiec \& Håkansson, 2000; Leão et al., 2004).

Os efeitos da compactação do solo na densidade, porosidade, retenção de água e resistência mecânica à penetração podem ser integrados em um único índice (Silva et al., 2010), denominado de Intervalo Hídrico Ótimo (IHO). No entanto, Van Lier \& Gubiani (2015) apresentam uma série de questionamentos a esse índice, tais como a utilização de valores fixos para alguns atributos, como a resistência mecânica crítica do solo à penetração, além de tensões predefinidas para capacidade de campo e ponto de murcha permanente. Assim, para que o IHO expresse a qualidade física e estrutural do solo, e possa ser usado na avalição do efeito desta qualidade sobre o crescimento de plantas, é necessário que se estabeleçam limites críticos adequados a cada cultura.

Nesse contexto, espera-se que o revolvimento proporcionado pela escarificação em solo compactado altere seus atributos físicos e mecânicos, e interfira no crescimento de raízes e na produtividade das culturas.

O objetivo deste trabalho foi caracterizar a compactação do solo e avaliar o efeito da escarificação anual nas entrelinhas de plantio na produtividade de soqueiras de cana-de-açúcar no Cerrado.

\section{Material e Métodos}

O experimento foi implantado em área de produção da Usina Goiasa Agrícola S/A, no município de Bom Jesus de Goiás, GO (Figura 1 A). A região está inserida no bioma Cerrado e possui clima do tipo Aw, na classificação de Köppen, caracterizado como tropical úmido, com duas estações bem definidas: úmida no verão, com chuvas concentradas nos meses de dezembro a março; e seca no inverno (Figura $1 \mathrm{~B}$ ). A precipitação pluvial média anual varia entre 1.200 e $1.800 \mathrm{~mm}$, e as temperaturas mínimas e máximas variam entre 1 e $40^{\circ} \mathrm{C}$. A litologia predominante é composta por basalto, da formação Serra Geral, e o relevo regional predominante varia de suave-ondulado a ondulado (Santos \& Sparovek, 2011).

O solo é classificado como Latossolo Vermelho acriférrico típico, textura muito argilosa, tendo no horizonte A (0 a $20 \mathrm{~cm}$ ) $662 \mathrm{~g} \mathrm{~kg}^{-1}$ de argila, $221 \mathrm{~g} \mathrm{~kg}^{-1}$ de silte e $118 \mathrm{~g} \mathrm{~kg}^{-1}$ de areia; e, no horizonte Bw (80 a $100 \mathrm{~cm}$ ), $681 \mathrm{~g} \mathrm{~kg}^{-1}$ de argila, $210 \mathrm{~g} \mathrm{~kg}^{-1}$ de silte e $109 \mathrm{~g} \mathrm{~kg}^{1}$ de areia. No horizonte $\mathrm{B}, \mathrm{pH} \mathrm{H}_{2} \mathrm{O}$ foi de 6,02 ,

Pesq. agropec. bras., Brasília, v.51, n.9, p.1610-1622, set. 2016 DOI: $10.1590 / \mathrm{S} 0100-204 X 2016000900061$ 
a soma de bases trocáveis (S) foi de $0,93 \mathrm{cmol}_{\mathrm{c}} \mathrm{kg}^{-1} \mathrm{e} \mathrm{o}$ Al trocável foi de $0,03 \mathrm{cmol}_{\mathrm{c}} \mathrm{kg}^{-1}$; enquanto que o valor de $\mathrm{S}$ mais o valor de $\mathrm{Al}$ extraível $\left(\mathrm{KCl} 1 \mathrm{~mol} \mathrm{~L}^{-1}\right)$ foi de $1,40 \mathrm{cmol}_{\mathrm{c}} \mathrm{kg}^{-1}$ de argila, e o $\mathrm{pH}$ em $\mathrm{KCl}\left(1 \mathrm{~mol} \mathrm{~L}^{-1}\right)$ foi de 6,17 e o $\Delta \mathrm{pH}$, de 0,15 , o que caracteriza o caráter ácrico (Santos et al., 2013).

A área foi cultivada com grãos até início de 2008, quando foi implantada a cultura da cana-de-açúcar variedade SP 86155, em abril, no espaçamento de 1,5 m entre linhas. Para tanto, foi realizada uma subsolagem seguida de gradagem pesada para incorporação de 4,36 $\mathrm{Mg} \mathrm{ha}^{-1}$ de calcário dolomítico. Na cana-planta, foram aplicados $30 \mathrm{~kg} \mathrm{ha}^{-1}$ de N, $170 \mathrm{~kg} \mathrm{ha}^{-1}$ de $\mathrm{P}_{2} \mathrm{O}_{5}$ e $140 \mathrm{~kg} \mathrm{ha}^{-1}$ de $\mathrm{K}_{2} \mathrm{O}$. Nas soqueiras, foram aplicados anualmente sobre a palhada na superfície do solo entre 80 e $100 \mathrm{~kg} \mathrm{ha}^{-1}$ de $\mathrm{N}$ e 96 a $120 \mathrm{~kg} \mathrm{ha}^{-1}$ de $\mathrm{K}_{2} \mathrm{O}$. Os critérios de escolha da área foram: solo de textura muito argilosa e colheita no início da safra (normalmente no fim do período chuvoso); condições estas que favorecem a compactação do solo pela maior frequência de tráfego em solo com teor de água elevado.

Antes do primeiro corte da cana, em abril de 2009, foi demarcada a área experimental (Figura $1 \mathrm{C}$ ), com parcelas de $50 \mathrm{~m}$ de comprimento e nove linhas, com área útil formada pelas cinco linhas centrais. Utilizouse o delineamento de blocos ao acaso, com quatro repetições e dois tratamentos: com e sem escarificação nas entrelinhas. Entre um bloco e outro, adotou-se a distância de $10 \mathrm{~m}$ de bordadura. Antes da colheita mecânica da área, a produtividade do primeiro corte (cana planta) foi avaliada mediante colheita e pesagem manual de $10 \mathrm{~m}$, das quatro linhas centrais da bordadura de cada bloco. No mesmo local (bordadura entre blocos), foram abertas trincheiras para caracterização inicial do solo, e coletadas amostras indeformadas para caracterização física (anéis cilíndricos com diâmetro e altura de $5 \mathrm{~cm}$ ), em cinco camadas -0 a $5 ; 5$ a $10 ; 10$ a 20; 20 a 40 e 40 a $60 \mathrm{~cm}$ - e em cinco posições: na linha de plantio, e a 30 e $60 \mathrm{~cm}$ do centro da linha, em cada lado, num total de 25 amostras por trincheira (100 amostras ao todo). Após cinco dias, a área total, restante das bordaduras, parcelas e de todo talhão, foi colhida mecanicamente.

A primeira escarificação foi realizada em maio de 2009, cerca de 40 dias após a colheita mecânica do restante da área, no momento em que a altura da brotação estava com aproximadamente $40-50 \mathrm{~cm}$

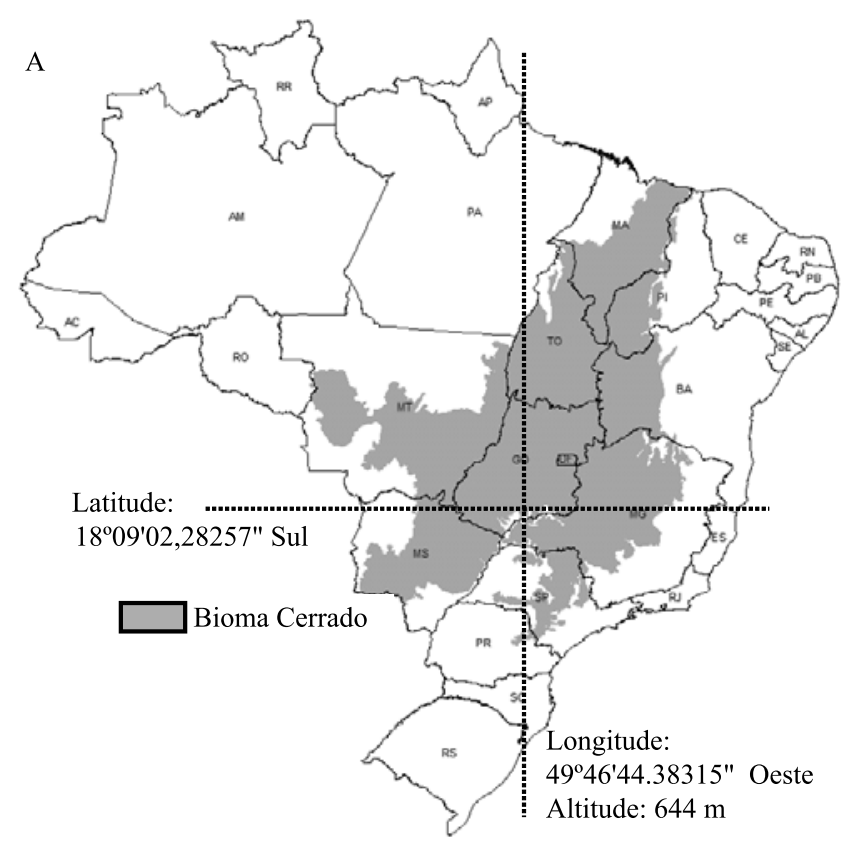

B

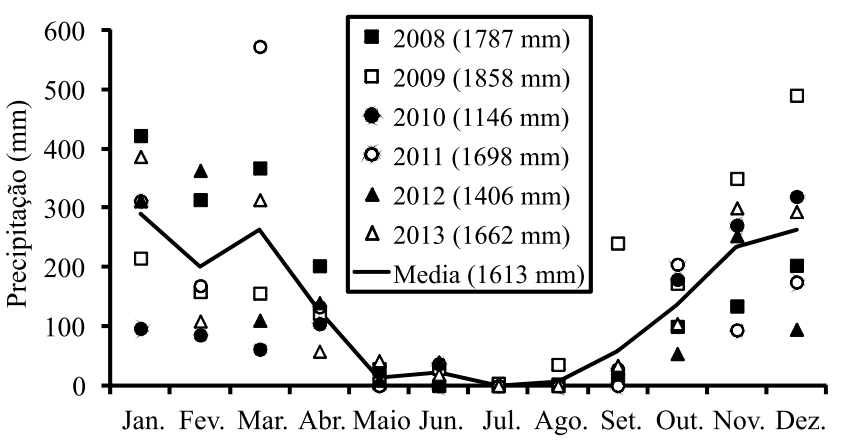

C

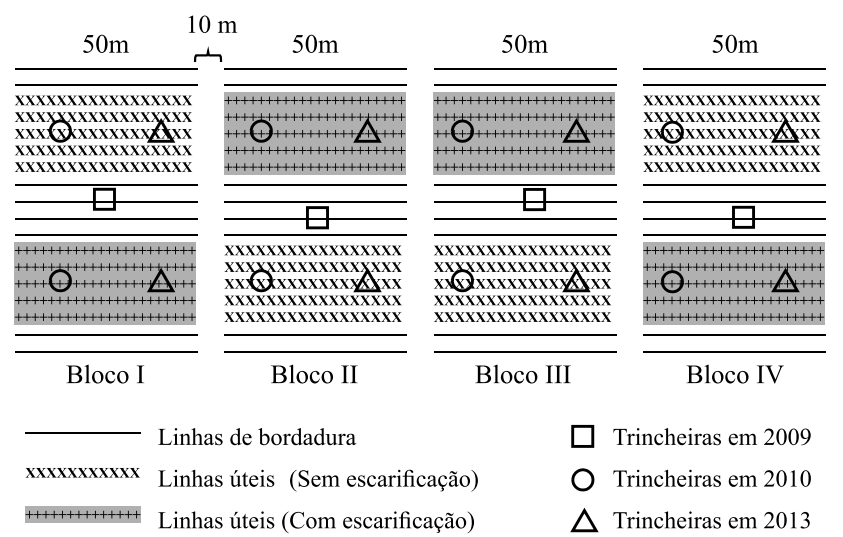

Figura 1. Localização da área experimental no bioma Cerrado (A); precipitação pluvial obtida na área da usina Goiasa Agrícola S/A, durante o período 2008-2013 (B); e croquis do experimento evidenciando o esquema de abertura de trincheiras $(\mathrm{C})$. 
de altura. Foi utilizado um escarificador, com duas hastes, operado a $30 \mathrm{~cm}$ de profundidade no centro da entrelinha (a $75 \mathrm{~cm}$ das linhas), tracionado por um trator. As escarificações após o segundo, terceiro e quarto cortes seguiram os mesmos procedimentos. Embora o escarificador fosse equipado com caixa para aplicação de fertilizantes, a adubação das soqueiras foi realizada em superfície, ao longo de todo experimento.

Avaliações de produtividade no segundo, terceiro e quarto cortes (primeira, segunda e terceira soca) foram feitas em maio de 2010, 2011 e 2012, respectivamente. No quinto corte (quarta soca), essa avaliação foi feita excepcionalmente em outubro de 2013, devido a um incêndio acidental ocorrido no fim do período seco de 2012, o qual queimou a brotação e alterou o calendário de colheita. Em cada soca, cortaram-se $10 \mathrm{~m}$, das cinco linhas úteis de cada parcela; ou seja: em 2010, foram cortados os $10 \mathrm{~m}$ iniciais de cada parcela; em 2011, de 10 a $20 \mathrm{~m}$, e assim por diante. Em cada parcela, foi retirada uma amostra de dez colmos para avaliação do teor de açúcar (açúcar total recuperável, ATR) conforme o Consecana... (2006). Os dados de produtividade de colmos e de açúcar na safra 2009, antes da implantação dos tratamentos, foram indicados na forma de média \pm erro-padrão, a 5\% de probabilidade de erro. $\mathrm{Na}$ avaliação dos resultados das safras de 2010, 2011, 2012 e 2013, utilizou-se o teste de Tukey a 5\% de probabilidade para estimar o contraste entre os tratamentos.

Nos anos de 2010 e 2013, após a colheita manual nas bordaduras entre blocos, e antes da colheita mecânica da área, foram abertas trincheiras para coleta de amostras deformadas e indeformadas de solo (Figura 1 C), em cinco camadas: 0 a $5 ; 5$ a $10 ; 10$ a 20; 20 a 40 e 40 a $60 \mathrm{~cm}$. Em razão da dificuldade de se coletar amostras na linha da cana, pela presença do rizoma mais desenvolvido na soqueira, optou-se por coletá-las nas posições 20,$0 ; 37,5$ e $75,0 \mathrm{~cm}$ do centro da linha de plantio, em cada um dos lados, o que resultou num total de 30 amostras por trincheira (120 amostras por tratamento).

As amostras para avaliação de raízes foram coletadas com trado caneco, tendo-se retirado 45 amostras de solo por parcela, nos anos de 2009 e 2010, em três pontos aleatoriamente distribuídos ao redor de cada trincheira, nas mesmas camadas e posições amostradas nas trincheiras, em cada ano. As amostras foram processadas conforme Kanno et al. (1999), e a massa específica de raízes obtida foi expressa em $\mathrm{kg}$ de massa seca de raízes por $\mathrm{m}^{3}$ de solo.

Nas amostras indeformadas, determinou-se a densidade do solo (Ds) conforme Claessen (1997). O grau de compactação (GC), expresso em percentagem, foi calculado pela expressão $\mathrm{GC}=100 \mathrm{Ds} / \mathrm{Ds}_{\mathrm{ref}}$, em que Ds é a densidade do solo e $\mathrm{Ds}_{\text {ref }}$ é a densidade de referência, determinada em amostras indeformadas de $50 \mathrm{~mm}$ de diâmetro por $20 \mathrm{~mm}$ de altura, equilibradas na tensão de $33 \mathrm{kPa}$ em câmara de pressão, e posteriormente submetidas à pressão de $1.600 \mathrm{kPa}$ em consolidômetro, conforme Suzuki et al. (2007).

No cálculo do intervalo hídrico ótimo, conforme Silva et al. (1994), as amostras foram saturadas e submetidas a oito níveis de tensão mátrica (h): $3,6,10,33,60,80$, 100 e $1.500 \mathrm{kPa}$. Uma vez equilibradas, determinouse a resistência à penetração com minipenetrômetro dinâmico (Sá et al., 2007b), e o cálculo da resistência foi feito conforme Stolf (1991). Para tanto, no ano de 2009, foram utilizadas 75 amostras provenientes de três trincheiras escolhidas ao acaso e distribuídas aleatoriamente em oito grupos (tensões 6, 10 e 100 $\mathrm{kPa}$, dez amostras; demais tensões, nove amostras por grupo). No ano de 2010, foram utilizadas 120 amostras por tratamento (15 amostras por tensão mátrica). A curva de resistência mecânica à penetração $(\mathrm{RP})$ foi ajustada a um modelo não linear, descrito por Busscher (1990): $\mathrm{RP}=\mathrm{a} \times \theta^{\mathrm{b}} \times \mathrm{Ds}^{\mathrm{c}}$, em que: RP é dado em MPa; a, b, c são parâmetros ajustados do modelo; $\theta$ é o teor de água (volumétrico) do solo, em $\mathrm{cm}^{3} \mathrm{~cm}^{-3}$; e Ds é a densidade do solo $\left(\mathrm{g} \mathrm{cm}^{-3}\right)$. A curva de retenção de água foi ajustada conforme alteração proposta por Leão et al. (2004): $\theta=\mathrm{d} \times \mathrm{Ds}^{\mathrm{e}} \times \mathrm{h}^{\mathrm{f}}$, em que: $\mathrm{d}$, e, f são parâmetros ajustados do modelo; e h é a tensão mátrica de água no solo, em $\mathrm{kPa}$. As curvas de resistência mecânica à penetração e características de retenção de água foram ajustadas aos dados dos anos de 2009 (cana-planta) e 2010 (primeira soca, com e sem escarificação), e as comparações entre as respectivas curvas foram feitas pelo teste de F, conforme Motulsky \& Christopoulos (2003).

Foram considerados dois valores críticos de resistência mecânica à penetração: o valor $2,0 \mathrm{Mpa}$, proposto por Otto et al. (2011) como limitante ao crescimento de raízes de cana-de-açúcar; e um valor alcançado no presente estudo, obtido ao igualar-se a zero a equação dos valores médios de massa específica de raízes ajustada por regressão linear à resistência à 
penetração, corrigida para o teor de água equivalente à tensão mátrica de $6 \mathrm{kPa}$, que foi considerada como próxima da capacidade de campo (Gonçalves et al., 2014). Da mesma forma, foram determinados valores críticos ao crescimento de raízes da densidade do solo e do grau de compactação. A tensão mátrica de 1.500 $\mathrm{kPa}$ foi considerada como ponto de murcha permanente (Silva et al., 1994).

O efeito da escarificação na massa específica de raízes (2010) e na densidade do solo foi avaliado isoladamente em 2010 e 2013 , em cada posição de amostragem - 20,0,37,5 e 75,0 cm, dentro de cada uma das cinco camadas de solo amostradas -, com o uso do teste de $\mathrm{t}$ a $5 \%$ de probabilidade. Os resultados médios de cada tratamento foram espacializados ao longo do perfil do solo, a partir do inverso do quadrado da distância, com o aplicativo Arc-View v.3.2, conforme Sá et al. (2007a).

\section{Resultados e Discussão}

As produtividades foram, em geral, adequadas ao padrão da região (Figura 2), com exceção da obtida na segunda soca (2011), que provavelmente foi prejudicada pela distribuição de chuvas em 2010, abaixo da média anual nos meses de janeiro a março (Figura $1 \mathrm{~B}$ ). Entretanto, nas quatro socas avaliadas, as produtividades não foram afetadas pela escarificação do solo nas entrelinhas da cultura (Figura 2). De forma análoga, outros trabalhos também não relataram efeito da escarificação de soqueiras na produtividade da cana, em Latossolos de textura média na região norte do Paraná (Paulino et al., 2004), com $260 \mathrm{~g} \mathrm{~kg}^{-1} \mathrm{de}$ argila, e no Mato Grosso (Bianchini et al., 2014), com $252 \mathrm{~g} \mathrm{~kg}^{-1}$ de argila.

Dados de massa específica de raízes foram plotados em função da densidade do solo, do grau de compactação e da resistência mecânica do solo à penetração (Figura 3). Somente $38 \%\left(\mathrm{R}^{2}=0,38\right)$ da redução da massa de raízes foi atribuída ao aumento da resistência mecânica do solo à penetração, enquanto $46 \%\left(R^{2}=0,46\right)$ foi atribuída ao aumento da densidade do solo e do grau de compactação. A elevada variabilidade dos dados (valores de $\mathrm{R}^{2}$ relativamente baixos) evidencia a interferência de outros fatores no crescimento de raízes, como a própria morfologia do sistema radicular, cuja massa de raízes tende a diminuir em função da profundidade e distância da planta, conforme demonstrado por Otto et al. (2011). Vasconcelos (2011) relata que a morfologia do sistema radicular varia também em função da variedade e idade do canavial (cana planta ou soca). Mesmo assim, as equações ajustadas foram significativas, o que confirma a tendência de redução da massa de raízes em função do aumento na compactação do solo.

O valor limitante de Ds obtido no presente trabalho foi de $1,33 \mathrm{~g} \mathrm{~cm}^{3}$, acima do qual não haveria crescimento de raízes (Figura $3 \mathrm{~A}$ ). Em solo com textura muito argilosa (600 $\mathrm{g} \mathrm{kg}^{-1}$ de argila), Vasconcelos (2011) relatou que porções do perfil com densidade em torno de $1,45 \mathrm{~g} \mathrm{~cm}^{-3}$ não continham raízes de cana-de-açúcar. Entretanto, essa espécie parece ser mais tolerante a compactação do que outras culturas. De Maria et al. (1999) verificaram em Latossolo Vermelho distroférrico muito argiloso (750 $\mathrm{g} \mathrm{kg}^{-1}$ de argila) que,
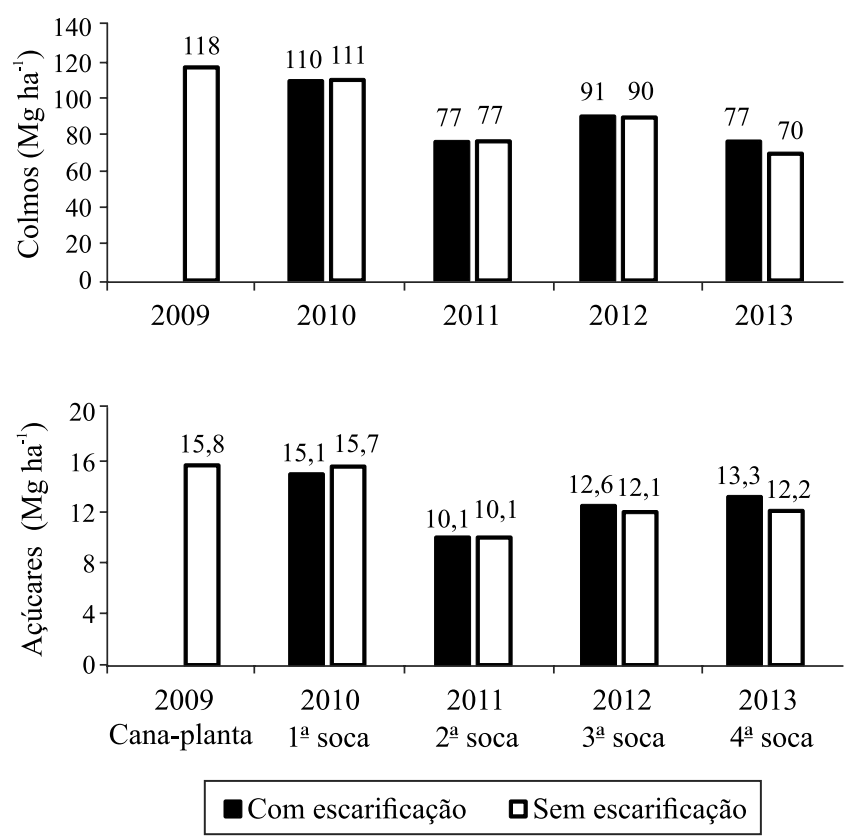

Figura 2. Produtividade de colmos e de açúcar nas safras 2009, 2010, 2011, 2012 e 2013 da variedade SP86155, em Latossolo Vermelho acriférrico típico, textura muito argilosa, nas condições com e sem escarificação, em área de produção da Usina Goiasa, no município de Bom Jesus, GO. DMS: diferença mínima significativa pelo teste de Tukey, a 5\% de probabilidade. DMS e CV (\%) para colmos: 2010 , 10,9 e 4,$4 ; 2011,10,7$ e 6,$2 ; 2012,22,9$ e 11,3 ; e $2013,27,3$ e 16,5.DMS e CV (\%) para açúcares: $2010,1,9$ e 5,4; 2011 , 2,5 e 11,$0 ; 2012,1,2$ e 3,2 ; e $2013,4,1$ e 14,1 . 
em densidade de $1,21 \mathrm{~g} \mathrm{~cm}^{-3}$, o crescimento radicular de soja foi afetado.

Para o solo em questão, a densidade máxima de referência foi de $1,51 \mathrm{~g} \mathrm{~cm}^{-3}$, e o grau de compactação limitante ao crescimento de raízes da cana foi de $87,9 \%$ (Figura 3 B). Nas condições edáficas da Suécia, país nórdico, Håkansson \& Lipiec (2000) relataram valores ótimos de grau de compactação para produtividade de culturas em torno de $87 \%$, independentemente da textura do solo. Entretanto, Reichert et al. (2009) alertam que respostas diferenciadas de rendimento das culturas em função do grau de compactação podem ser encontradas na literatura, de acordo com o método utilizado para determinação da densidade de referência. Segundo os autores, a utilização de consolidômetros para aplicação de $200 \mathrm{kPa}$ de pressão em amostras deformadas, conforme proposto por Håkansson \& Lipiec (2000), aplica-se a solos revolvidos anualmente, como é feito em cultivos de grãos na Europa, mas tem gerado valores baixos de densidade de referência e elevados de grau de compactação - muitas vezes acima de $100 \%$ - em solos não revolvidos, como no sistema plantio direto. Assim, o método utilizado no presente estudo, com aplicação de $1.600 \mathrm{kPa}$ de pressão (Suzuki et al., 2007), ou com o uso do ensaio de Proctor, com energia de compactação de $597 \mathrm{~kJ} \mathrm{~m}^{-3}$ tem sido indicado como adequado na determinação da densidade de referência do solo em soqueiras de canade-açúcar, em que não há revolvimento anual do solo.

O grau de compactação do solo normalmente tem efeito quadrático sobre a produtividade, em que se observam aumentos até certo grau de compactação, considerado ótimo, a partir do qual ela começa a diminuir. Santos et al. (2005) observaram máxima produtividade de matéria seca da parte aérea de milho com o grau de compactação de $65 \%$, e redução drástica a partir de 75\%. Alves et al. (2003) observaram produtividade máxima de matéria seca do feijoeiro com o grau de compactação de $70 \%$, e redução a partir daí. Nesses trabalhos, a densidade de referência foi determinada com base no ensaio de Proctor, e os valores ótimos para produtividade estiveram abaixo dos valores críticos no presente estudo.

Para a resistência à penetração, o valor crítico de 3,8 MPa foi determinado (Figura $3 \mathrm{C}$ ). Este valor está bem acima dos 2,0 $\mathrm{MPa}$, propostos por Otto et al. (2011) como críticos ao crescimento de raízes da cultivar SP813250, em Latossolo com textura média
(347 $\mathrm{g} \mathrm{kg}^{-1}$ de argila), com uso de um penetrômetro com velocidade de penetração constante. Embora trate-se de solos e cultivares distintas, penetrômetros
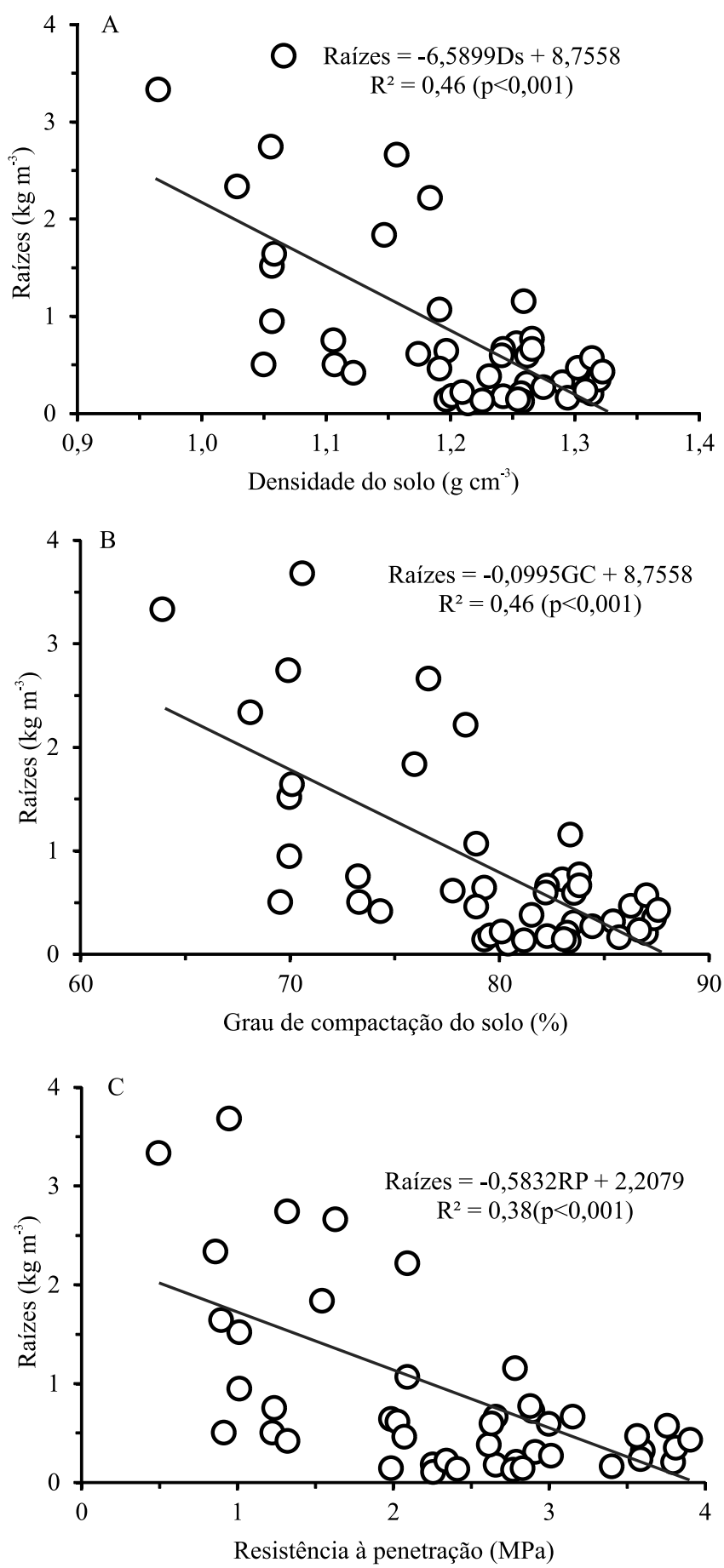

Figura 3. Relações da massa específica de raízes com: A, densidade do solo (Ds); B, grau de compactação do solo $(\mathrm{GC})$; e C, resistência mecânica à penetração $(\mathrm{RP})$ corrigida para teor de água equivalente à tensão mátrica de $6 \mathrm{kPa}$. 
dinâmicos, ou de impacto, como o utilizado no presente estudo podem fornecer valores mais elevados de resistência mecânica à penetração, sobretudo em solos argilosos, conforme Stolf (1991) e Beutler et. al. (2007). Entretanto, na literatura parece não haver consenso quanto ao valor de resistência mecânica à penetração limitante da cana-de-açúcar. Gonçalves et al. (2014) utilizaram 2,5 MPa, enquanto Cavalieri et al. (2011) e Souza et al. (2015) utilizaram 3,0 MPa. Por sua vez, Veen \& Boone (1990) observaram que o crescimento de raízes de milho foi totalmente inibido em um valor de resistência mecânica à penetração de 4,2 MPa. Entretanto, os autores advertem que a resistência oferecida pelo solo à haste do penetrômetro tende a ser maior do que a efetivamente exercida sobre as raízes, conforme também observado por Van Lier \& Gubiani (2015). Contudo, Tavares Filho et al. (2001) afirmam que, se houverem condições químicas e umidade favorável, e se a porosidade do solo permitir que ocorra difusão de oxigênio, as raízes podem sofrer deformações morfológicas e crescer através de pontos de menor resistência, mesmo em solo com valores elevados de resistência mecânica à penetração. Esse crescimento pode acontecer, sobretudo, por meio de macroporos e canais formados após a senescência de antigas raízes (Unger \& Kaspar, 1994).

Todos os modelos ajustados geraram coeficientes significativos $(\mathrm{p}<0,01)$ e valores de $\mathrm{R}^{2}$ elevados (Tabela 1). No entanto, os contrastes não revelaram diferenças significativas nos modelos entre 2009 e 2010 , o que indica que as relações da resistência mecânica à penetração com a Ds ou com o teor de água no solo, bem como a relação do teor de água com a densidade e tensão mátrica (curva de retenção de água), não foram alteradas nesses anos. Em 2010, essas relações também não foram afetadas pela escarificação. Assim, os dados foram agrupados e ajustados aos modelos 7 e $8(n=314)$, para resistência a penetração $\left(R^{2}=0,79\right)$ e retenção de água $\left(\mathrm{R}^{2}\right.$ de 0,76$)$, respectivamente, ambos com coeficientes significativos a $1 \%$ de probabilidade.

Com base nesses modelos, foram construídos os diagramas de Intervalo Hídrico Ótimo, tendo-se considerado, nas abscissas, a densidade do solo e o grau de compactação, e, nas ordenadas, o teor de água volumétrico ou a porosidade do solo (Figura 4). Ao se considerar o valor limitante da resistência mecânica à penetração de 2,0 Mpa, proposto por Otto et al. (2011), a densidade crítica no presente estudo seria $1,2 \mathrm{~g} \mathrm{~cm}^{-3}$, que corresponderia a um grau de compactação de $80 \%$. Embora esses valores sejam próximos aos observados por De Maria et al. (1999) para soja, respectivamente de 2,09 MPa e 1,21 $\mathrm{g} \mathrm{cm}^{-3}$, em solo semelhante ao do presente estudo, é possível observar na Figura 4 que algumas amostras apresentaram Ds superior a $1,2 \mathrm{~g} \mathrm{~cm}^{-3}$, sobretudo nas coletas feitas em 2010 e 2013. Na Figura 5, observou-se que as raízes da cana-de-açúcar estavam presentes mesmo em densidade acima de $1,2 \mathrm{~g} \mathrm{~cm}^{-3}$, e que sua distribuição esteve mais relacionada à morfologia da planta do que a valores limitantes de densidade do solo. Resultados semelhantes foram relatados para esta cultura por Otto et al. (2011) e Vasconcelos (2011).

Ao se tomar como referência a RP limitante de 3,8 $\mathrm{MPa}$, os diagramas foram divididos em três regiões: $\mathrm{R} 1$, R2 e R3 (Figura 4). A região R1 compreende valores de grau de compactação menor que $74,2 \%$ (Ds $<1,12$ $\mathrm{g} \mathrm{cm}^{-3}$ ), na qual a resistência de $3,8 \mathrm{MPa}$ ocorre quando o teor de água é igual ou inferior ao ponto de murcha. Nessa condição não existem limitações físicas ao crescimento das raízes. Parte das amostras coletadas em 2009, antes da colheita da cana planta, encontravase nessa faixa. Nessa época, densidades mais elevadas podiam ser observadas nas entrelinhas (Figura 5), com poucos valores acima de $1,33 \mathrm{~g} \mathrm{~cm}^{-3}$, provavelmente em decorrência do tráfego de máquinas durante as operações de sulcagem, plantio e "quebra lombo" (operação realizada após a brotação da cana planta com objetivo de desmanchar camalhões formados durante a abertura dos sulcos de plantio). Na região R2 (Figura 4), o grau de compactação do solo variou entre 74,2 e $87,9 \%$ (Ds entre 1,12 e $1,33 \mathrm{~g} \mathrm{~cm}^{-3}$ ), portanto com ocorrência de impedimentos físicos, uma vez que a RP limitante ocorre entre a capacidade de campo e o ponto de murcha, que foi a situação de umidade observada em parte das amostras coletadas em 2010 e 2013. Entretanto, uma quantidade substancial de amostras coletadas em 2010 situou-se na região R3, com limitações ao crescimento de raízes e valores de densidade mais elevados ao longo do perfil do solo, associados a valores mais baixos de Intervalo Hídrico Ótimo, sobretudo ao longo das entrelinhas e camadas superficiais (Figura 5).

Mesmo havendo diferenças entre a forma como a haste do penetrômetro e as raízes penetram no solo, conforme relatado na literatura (Venn \& Boone, 1990; Unger \& Kaspar, 1994; Van Lier \& Gubiani, 
2015), valor de RP de 3,8 MPa parece estar mais bem relacionado com a distribuição de raízes do que o valor de 2,0 Mpa, para as condições de solo e variedade usadas no presente estudo.

Não houve efeito da escarificação na Ds, em 2010 e 2013 (Figura 5). Em ambas as condições (com e sem escarificação), foram determinados valores de densidade em torno de $1,0 \mathrm{~g} \mathrm{~cm}^{-3}$, na camada superficial próxima à linha, e em torno de 1,2 a $1,3 \mathrm{~g} \mathrm{~cm}^{-3}$, na entrelinha. A densidade do solo, próximo da linha de plantio, tende a aumentar em profundidade.

Resultados semelhantes foram observados para o Intervalo Hídrico Ótimo (Figura 5), os quais corroboraram as observações de Tim Chamen et al.

Tabela 1. Estatística descritiva das variáveis físicas do solo utilizadas para ajuste dos modelos, com respectivos coeficientes de determinação $\left(\mathrm{R}^{2}\right)$.

\begin{tabular}{|c|c|c|c|c|c|c|c|}
\hline Variável & $\mathrm{N}$ & Media & Desvio-Padrão & Mínimo & Máximo & Modelos Ajustados' & $\mathrm{R}^{2}$ \\
\hline & \multicolumn{7}{|c|}{ Cana planta safra 2009} \\
\hline $\mathrm{RP}$ & 75 & 2,366 & 1,720 & 0,121 & 7,142 & Modelo 1 & \\
\hline Ds & 75 & 1,128 & 0,107 & 0,893 & 1,363 & $\mathrm{RP}=0,05072 \theta^{-2,34093} \mathrm{Ds}^{8,55086}$ & 0,86 \\
\hline q & 75 & 0,348 & 0,061 & 0,230 & 0,496 & Modelo 2 & \\
\hline \multirow[t]{2}{*}{ h } & 75 & 213,776 & 475,784 & 3,000 & 1500,000 & $\theta=0,42065 \mathrm{Ds}^{0,84276} \mathrm{~h}^{-0,08438}$ & 0,86 \\
\hline & \multicolumn{7}{|c|}{ Primeira soca safra 2010, com escarificação } \\
\hline $\mathrm{RP}$ & 119 & 3,883 & 2,384 & 0,467 & 13,582 & Modelo 3 & \\
\hline Ds & 119 & 1,229 & 0,106 & 0,759 & 1,441 & $\mathrm{RP}=0,03875 \theta^{-2,60103} \mathrm{Ds}^{8,77054}$ & 0,75 \\
\hline$\theta$ & 119 & 0,364 & 0,065 & 0,217 & 0,539 & Modelo 4 & \\
\hline \multirow[t]{2}{*}{$\mathrm{h}$} & 119 & 225,042 & 487,399 & 3,000 & 1500,000 & $\theta=0,38256 \operatorname{Ds}^{0,93865} \mathrm{~h}^{-0,06920}$ & 0,73 \\
\hline & \multicolumn{7}{|c|}{ Primeira soca safra 2010, sem escarificação } \\
\hline $\mathrm{RP}$ & $119^{(9)}$ & 4,595 & 2,782 & 0,535 & 14,136 & Modelo 5 & \\
\hline Ds & 119 & 1,249 & 0,090 & 0,997 & 1,434 & $\mathrm{RP}=0,02027 \theta^{-3,23241} \mathrm{Ds}^{8,90404}$ & 0,76 \\
\hline q & 119 & 0,366 & 0,053 & 0,262 & 0,489 & Modelo 6 & \\
\hline \multirow[t]{2}{*}{$\mathrm{h}$} & 119 & 225,605 & 487,215 & 3,000 & 1500,000 & $\theta=0,38848 \operatorname{Ds}^{0,76031} \mathrm{~h}^{-0,06488}$ & 0,71 \\
\hline & \multicolumn{7}{|c|}{ Safras 2009 e 2010 , todos os dados } \\
\hline $\mathrm{RP}$ & 314 & 3,786 & 2,551 & 0,121 & 14,015 & Modelo 7 & \\
\hline DS & 314 & 1,212 & 0,111 & 0,759 & 1,441 & $\mathrm{RP}=0,03045 \theta^{-2,84880} \mathrm{Ds}^{8,82041}$ & 0,79 \\
\hline$\theta$ & 314 & 0,361 & 0,060 & 0,217 & 0,539 & Modelo 8 & \\
\hline \multirow[t]{8}{*}{$\mathrm{h}$} & 314 & 222,529 & 483,029 & 3,000 & 1500,000 & $\theta=0,39855 \mathrm{Ds}^{0,78373} \mathrm{~h}^{-0,07127}$ & 0,76 \\
\hline & \multicolumn{7}{|c|}{ Contraste entre os modelos ${ }^{(2)}$} \\
\hline & \multicolumn{3}{|c|}{ Modelo 1 Vs. Modelo 3} & & \multicolumn{2}{|r|}{$0,3579(\mathrm{p}=0,9999)$} & \\
\hline & \multicolumn{3}{|c|}{ Modelo 1 Vs. Modelo 5} & & \multicolumn{2}{|r|}{$0,3984(\mathrm{p}=0,9999)$} & \\
\hline & \multicolumn{3}{|c|}{ Modelo 3 Vs. Modelo 5} & & \multicolumn{2}{|r|}{$0,7646(\mathrm{P}=0,9266)$} & \\
\hline & \multicolumn{3}{|c|}{ Modelo 2 Vs. Modelo 4} & & \multicolumn{2}{|r|}{$0,5897(\mathrm{P}=0,9770)$} & \\
\hline & \multicolumn{3}{|c|}{ Modelo 2 Vs. Modelo 6} & & \multicolumn{2}{|r|}{$0,8443(\mathrm{P}=0,7369)$} & \\
\hline & \multicolumn{3}{|c|}{ Modelo 4 Vs. Modelo 6} & & & \multicolumn{2}{|l|}{$0,7249(\mathrm{P}=0,9589)$} \\
\hline
\end{tabular}

${ }^{(1)}$ Valores de $\mathrm{F}$ acompanhados da significância; em que $\mathrm{p}>0,05$ foram considerados não significativos. N, número de observações; RP, resistência à penetração (MPa); Ds, densidade do solo $\left(\mathrm{g} \mathrm{cm}^{-3}\right) ; \theta$, conteúdo volumétrico de água $\left(\mathrm{cm}^{3} \mathrm{~cm}^{-3}\right)$; h, tensão mátrica de água no solo $(\mathrm{kPa})$. ${ }^{(9)}$ Uma amostra perdida de cada tratamento em 2010. 
(2015), segundo as quais o efeito de práticas mecânicas de manejo da compactação, como a escarificação, é temporário, e desaparecem após cerca de um ano. Isso indica que as variações nos atributos físicos do solo observadas no presente estudo podem ser atribuídas ao tráfego, que era praticamente ausente nas linhas, mas presente nas entrelinhas. De acordo com Souza et al. (2015), é comum a utilização de tratores com bitola de
$1,5 \mathrm{~m}$, que tracionam transbordos com bitola de $2,0 \mathrm{~m}$, em canaviais com espaçamento entre linhas de $1,5 \mathrm{~m}$. Neste caso, uma trilha de rodagem é formada em uma faixa de aproximadamente $1,10 \mathrm{~m}$ na entrelinha $(73 \%$ da área cultivada). Isso faz com que apenas $20 \mathrm{~cm}$ de cada lado da linha de plantio fiquem sem rodagem, o que representa uma condição semelhante à verificada no presente estudo.
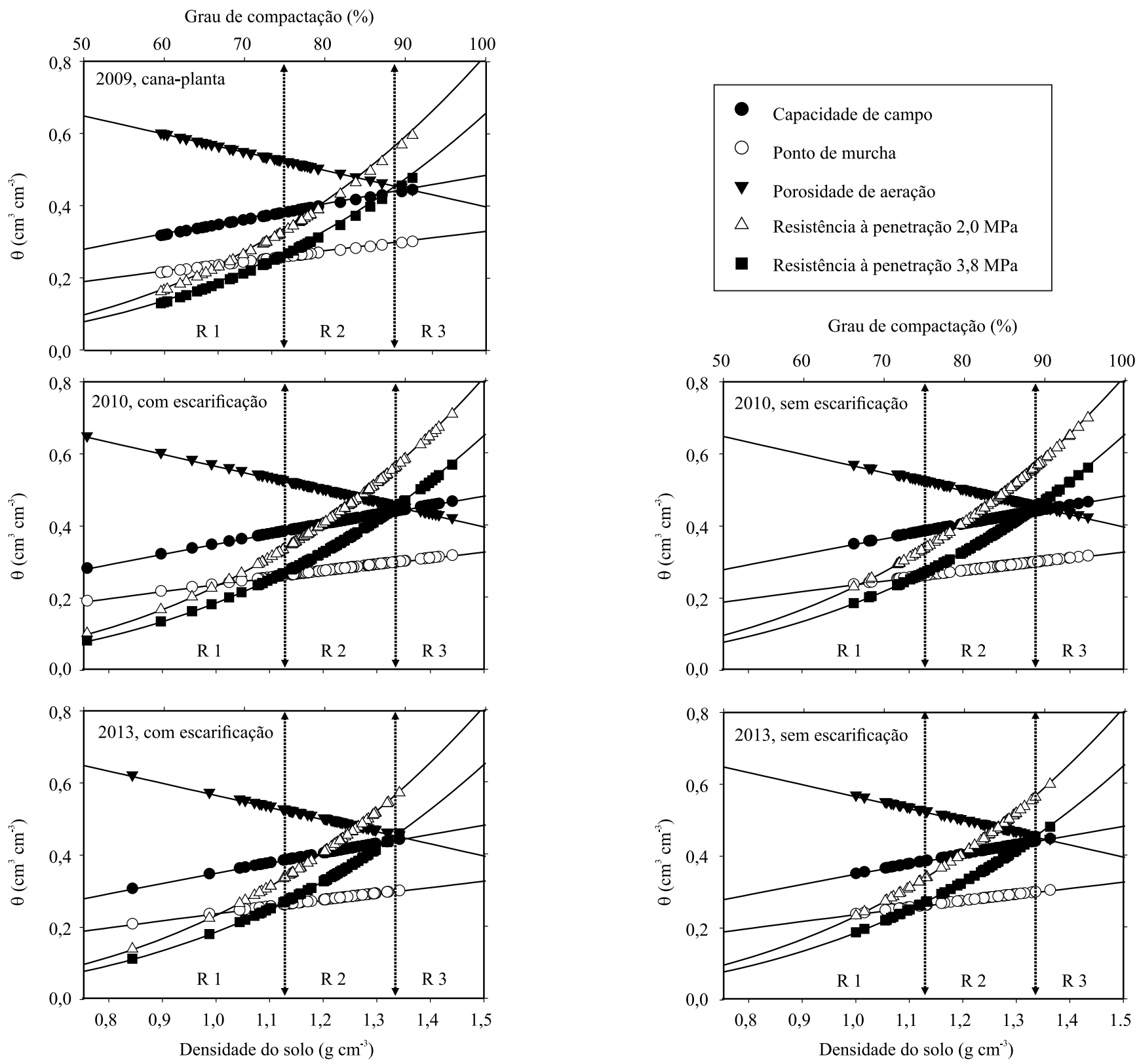

Figura 4. Diagramas de intervalo hídrico ótimo de Latossolo Vermelho acriférrico típico, textura muito argilosa, nos anos de 2009; 2010 e 2013. As regiões R1, R2 e R3 correspondem, respectivamente, à região sem impedimentos físicos ao crescimento de raízes; às regiões com impedimentos e limitações ao crescimento radicular. 
O conjunto trator-transbordo parece ser o grande responsável pela compactação do solo em canaviais (Souza, 2012). Nesse contexto, Tim Chamen et al. (2015) mencionam que se o solo for trafegado úmido, o dano a sua qualidade física é ainda maior. Assim, a padronização da bitola do maquinário em espaçamentos múltiplos ao da cultura concentraria todo o tráfego na menor faixa possível, no centro da entrelinha, o que parece ser uma prática adequada de manejo para reduzir a superfície compactada do solo nos canaviais. Souza et al. (2015) demonstraram melhorias da qualidade física do solo, na maior parte do perfil, quando o tráfego é realizado desta maneira, enquanto Souza (2012) relatou aumento da produtividade de colmos e de açúcar da ordem de 18 e $20 \%$, respectivamente, em canavial sob tráfego controlado. Isso corrobora as
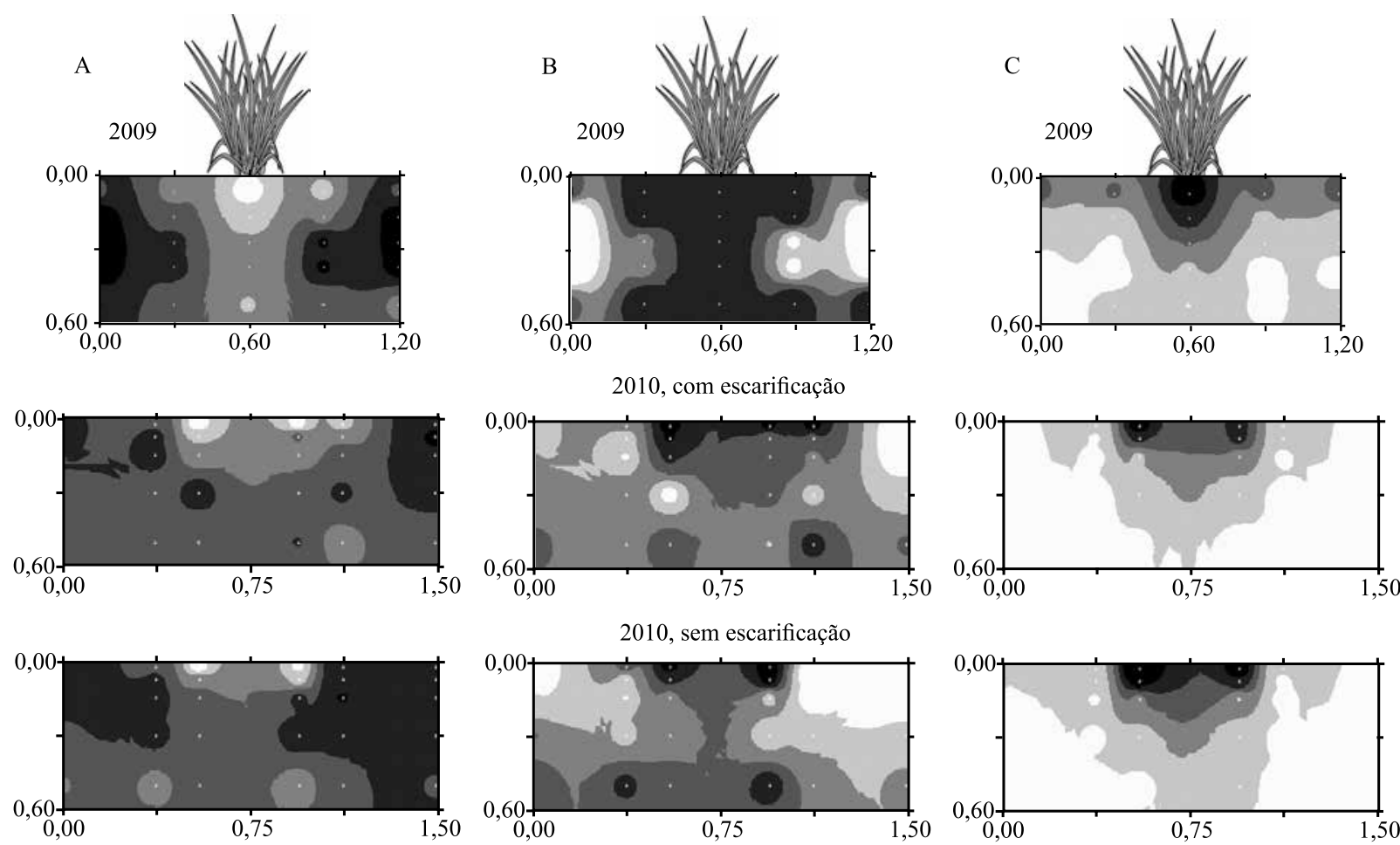

2013, com escarificação
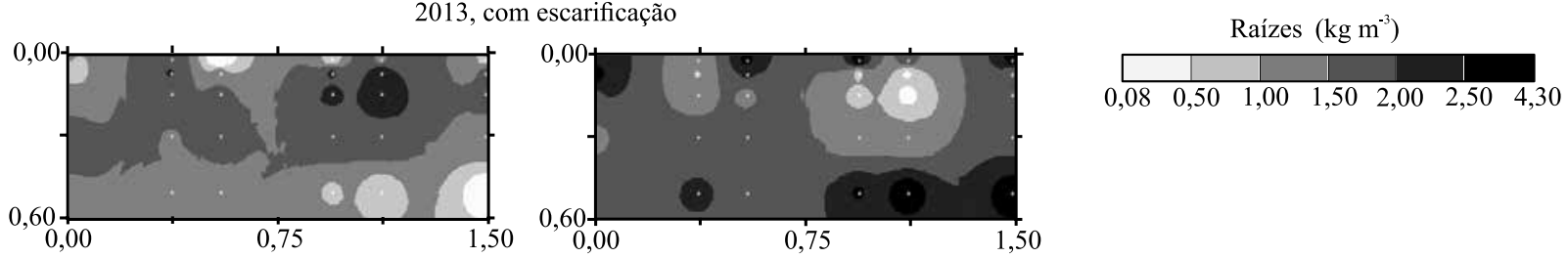

2013, sem escarificação
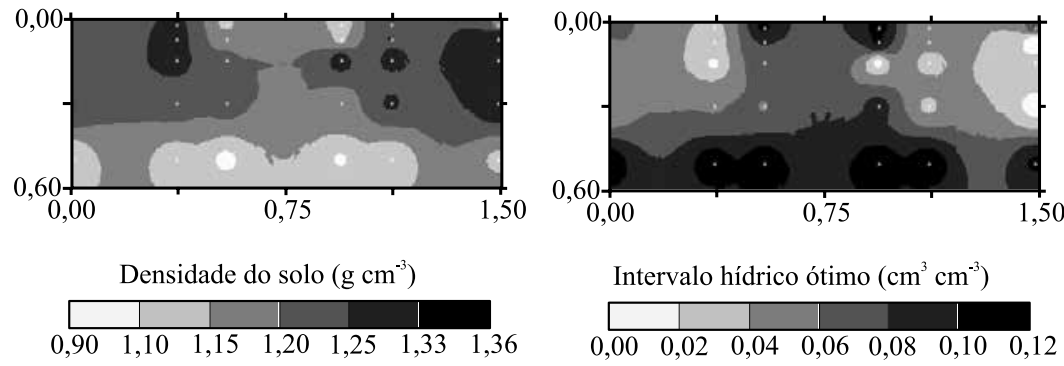

Intervalo hídrico ótimo $\left(\mathrm{cm}^{3} \mathrm{~cm}^{-3}\right)$

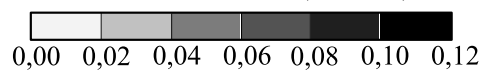

Figura 5. Distribuição espacial da densidade do solo (A), do intervalo hídrico ótimo (B) e da massa específica de raízes no perfil (C) de um Latossolo Vermelho acriférrico típico, nas condições estudadas. 
observações de Tim Chamen et al. (2015), segundo as quais práticas preventivas podem ser mais eficientes do que práticas mitigadoras da compactação do solo, como a escarificação.

Não foi observado efeito da escarificação do solo na massa específica de raízes das soqueiras, em nenhuma das posições e camadas de solo amostradas $(p>0,05)$, provavelmente pelo fato de que parte do sistema radicular da cana-de-açúcar é renovado após cada corte (Smith et al., 2005). Da mesma forma, a escarificação realizada em pós-colheita também não afetou a produtividade de colmos e de açúcar (Figura 2).

Houve predominância de raízes nas camadas superficiais e próximo das touceiras (Figura 5). Essa distribuição está de acordo com a observada por Otto et al. (2011) e Vasconcelos (2011). Em revisão bibliográfica, Smith et al. (2005) relataram que, embora o sistema radicular da cana-de-açúcar possa atingir grandes profundidades, de 2 a $6 \mathrm{~m}$, cerca de $50 \%$ da biomassa de raízes ocorrem nos $20 \mathrm{~cm}$ superficiais do solo, e $85 \%$ nos $60 \mathrm{~cm}$ superficiais. Valores semelhantes foram encontrados por Ohashi et al. (2015) na camada de $0-20 \mathrm{~cm}$ de profundidade. Entretanto, os autores observaram que $80 \%$ do sistema radicular encontra-se nos $40 \mathrm{~cm}$ superficiais. Vasconcelos (2011) menciona, no entanto, que esta distribuição também pode ser influenciada pela variedade de cana-de-açúcar.

\section{Conclusões}

1. A escarificação do solo nas entrelinhas da soqueira de cana-de-açúcar não interfere na massa de raízes, nos atributos físicos do solo ou na produtividade de colmos e de açúcar.

2. A densidade crítica do solo obtida para o crescimento de raízes da variedade SP 86155 é de $1,33 \mathrm{~g} \mathrm{~cm}^{-3}$, que corresponde ao grau de compactação de $87,9 \%$.

3. A resistência à penetração crítica do solo ao crescimento de raízes dessa variedade de cana-de-açúcar é de 3,8 MPa.

\section{Agradecimentos}

À Usina Goiasa Agrícola S/A, pelo apoio à condução deste trabalho; aos assistentes Jesuíno de Souza Caldas, Edson Douglas de Oliveira e Nelson Camargos Moreira, da Embrapa Cerrados, pelo auxílio nos trabalhos de campo.

\section{Referências}

ALVES, V.G.; ANDRADE, M.J.B. de; CORRÊA, J.B.D.; MORAES, A.R. de; SILVA, M.V. da. Concentração de macronutrientes na parte aérea do feijoeiro (Phaseolus vulgaris L.) em função da compactação e classes de solos. Ciência e Agrotecnologia, v.27, p.44-53, 2003. DOI: 10.1590/S141370542003000100005 .

BERNOUX, M.; ARROUAYS, D.; VOLKOFF, B.; CERRI, C.C.; JOLIVET, C. Bulk densities of Brazilian Amazon soils related to other soil properties. Soil Science Society of America Journal, v.62, p.743-749, 1998. DOI: 10.2136/ Sssaj1998.03615995006200030029x.

BEUTLER, A.N.; CENTURION, J.F.; SILVA, A.P. Comparação de penetrômetros na avaliação da compactação de latossolos. Engenharia Agrícola, v.27, p.146-151, 2007. DOI: 10.1590/S0100-69162007000100008.

BIANCHINI, A.; VALADÃO JUNIOR, D.D.; ROSA, R.P.; COLHADO, F.; DAROS, R.F. Soil chiseling and fertilizer location in sugarcane ratoon cultivation. Engenharia Agrícola, v.34, p.5765, 2014. DOI: 10.1590/S0100-69162014000100007.

BUSSCHER, W.J. Adjustment of flat-tipped penetrometer resistance data to a common water content. Transactions of the American Society of Agricultural Engineers, v.33, p.519-524, 1990. DOI: $10.13031 / 2013.31360$.

CAVALIERI, K.M.V.; CARVALHO, L.A. de; SILVA, A.P. da; LIBARDI, P.L.; TORMENA, A.C. Qualidade física de três solos sob colheita mecanizada de cana-de-açúcar. Revista Brasileira de Ciência do Solo, v.35, p.1541-1550, 2011. DOI: 10.1590/S010006832011000500008 .

CLAESSEN, M.E.C. (Org.). Manual de métodos de análise de solo. 2.ed. rev. atual. Rio de Janeiro: Embrapa-CNPS, 1997. 212 p. (Embrapa-CNPS. Documentos, 1)

CONSECANA. CONSELHO DOS PRODUTORES DE CANADE-AÇÚCAR, AÇÚCAR E ÁlCOOL DO ESTADO DE SÃO PAULO. Manual de instruções Consecana-SP. 5.ed. Piracicaba: Consecana, 2006. 112p.

DE MARIA, I.C.; CASTRO, O.M.; SOUZA DIAS, H. Atributos físicos do solo e crescimento radicular de soja em Latossolo Roxo sob diferentes métodos de preparo do solo. Revista Brasileira de Ciência do Solo, v.23, p.703-709, 1999. DOI: 10.1590/S010006831999000300025.

GONÇALVES, W.G.; SEVERIANO, E. da C.; SILVA, F.G.; COSTA, K.A. de P.; GUIMARÃES JUNNYOR, W. da S.; MELO, G.B. Least limiting water range in assessing compaction in a Brazilian Cerrado Latosol growing sugarcane. Revista Brasileira de Ciência do Solo, v.38, p.432-443, 2014. DOI: 10.1590/S010006832014000200008 .

HÅKANSSON, I.; LIPIEC, J. A review of the usefulness of relative bulk density values in studies of soil structure and compaction. Soil and Tillage Research, v.53, p.71-85, 2000. DOI: 10.1016/S01671987(99)00095-1.

KANNO, T.; MACEDO, M.C.; EUCLIDES, V.P.B.; BONO, J.A.; SANTOS JUNIOR, J.D.G.; ROCHA, M.C.; BERETTA, L.G.R. 
Root biomass of five tropical grass pastures under continuous grazing in Brazilian savannas. Grassland Science, v.45, p.9-14, 1999.

LEÃO, T.P.; SILVA, A.P.; MACEDO, M.C.M.; IMHOFF, S.; EUCLIDES, V.P.B. Intervalo hídrico ótimo na avaliação de sistemas de pastejo contínuo e rotacionado. Revista Brasileira de Ciência do Solo, v.28, p.415-423, 2004. DOI: 10.1590/S010006832004000300002.

LIPIEC, J.; HÅKANSSON, I. Influences of degree of compactness and matric water tension on some important plant growth factors. Soil and Tillage Research, v.53, p.87-94, 2000. DOI: 10.1016/ S0167-1987(99)00094-X.

MOTULSKY, H.; CHRISTOPOULOS, A. Fitting models to biological data using linear and nonlinear regression: a practical guide to curve fitting. Version 4.0. San Diego: GraphPad Software, 2003. Diaponível em: <www.graphpad.com>. Acesso em: 23 nov. 2006.

OHASHI, A.Y.P.; PIRES, R.C. de M.; RIBEIRO, R.V.; SILVA, A.L.B. de O. Root growth and distribution in sugarcane cultivars fertirrigated by a subsurface drip system. Bragantia, v.74, p.131138, 2015. DOI: 10.1590/1678-4499.0295.

OTTO, R.; SILVA, A.P.; FRANCO, H.C.J.; OLIVEIRA, E.C.A.; TRIVELIN, P.C.O. High soil penetration resistance reduces sugarcane root system development. Soil and Tillage Research, v.117, p.201-210, 2011. DOI: 10.1016/j.still.2011.10.005.

PAULINO, A.F.; MEDINA, C.C.; AZEVEDO, M.C.B.; SILVEIRA K.R.P.; TREVISAN, A.A.; MURATA, I.M. Escarificação de um Latossolo Vermelho na pós-colheita de soqueira de cana-de-açúcar. Revista Brasileira de Ciência do Solo, v.28, p.911-917, 2004. DOI: 10.1590/S0100-06832004000500013.

REICHERT, J.M.; SUZUKI, L.E.A.S.; REINERT, D.J.; HORN, R.; HAKANSSON, I. Reference bulk density and critical degreeof-compactness for no-till crop production in subtropical highly weathered soils. Soil and Tillage Research, v.102, p.242-254, 2009. DOI: 10.1016/j.still.2008.07.002.

SÁ, M.A.C. de; SANTOS JÚNIOR, J. de D.G. dos; MIRANDA, L.N. de. Avaliação do intervalo hídrico ótimo e sua relação com a produtividade e a massa de raízes de feijoeiro em sistema de plantio direto e preparo convencional do solo. Planaltina, DF: Embrapa Cerrados, 2007a. 28p. (Embrapa Cerrados. Boletim de pesquisa e desenvolvimento, 194).

SÁ, M.A.C. de; SANTOS JUNIOR, J. de D.G. dos; RESCK, D.V.S.; FERREIRA, E.A.B.; FRANZ, C.A.B. Minipenetrômetro dinâmico para determinação da resistência à penetração em amostras de solo indeformadas. Pesquisa Agropecuária Brasileira, v.42, p.16591662, 2007b. DOI: 10.1590/S0100-204X2007001100019.

SANTOS, D.S. dos; SPAROVEK, G. Retenção de sedimentos removidos de área de lavoura pela mata ciliar, em Goiatuba (GO). Revista Brasileira de Ciência do Solo, v.35, p.1811-1818, 2011. DOI: $10.1590 / \mathrm{S} 0100-06832011000500035$.

SANTOS, G.A. dos; DIAS JUNIOR, M. de S.; GUIMARÃES, P.T.G.; FURTINI NETO, A.E. Diferentes graus de compactação e fornecimento de fósforo influenciando no crescimento de plantas de milho (Zea mays L.) cultivadas em solos distintos. Ciência e
Agrotecnologia, v.29, p.740-752, 2005. DOI: 10.1590/S141370542005000400005 .

SANTOS, H.G. dos; JACOMINE, P.K.T.; ANJOS, L.H.C. dos; OLIVEIRA, V.A. de; LUMBRERAS, J.F.; COELHO, M.R.; ALMEIDA, J.A. de; CUNHA, T.J.F.; OLIVEIRA, J.B. de. Sistema brasileiro de classificação de solos. 3.ed. rev. e ampl. Brasília, DF: Embrapa, 2013. 353p.

SILVA, A.P. da; KAY, B.D.; PERFECT, E. Characterization of the least limiting water range. Soil Science Society of America Journal, v.58, p.1775-1781, 1994. DOI: 10.2136/ sssaj1994.03615995005800060028x.

SILVA, A.P.; TORMENA, A.C.; DIAS JUNIOR, M.S.; IMHOFF, S.; KLEIN, V.A. Indicadores de qualidade física do solo. In: VAN LIER, Q. de J. (Ed.). Física do solo. Viçosa: Sociedade Brasileira de Ciência do Solo, 2010. p.241-281.

SMITH, D.M.; INMAN-BAMBER, N.G.; THORBURN, P.J. Growth and function of the sugarcane root system. Field Crops Research, v.92, p.169-183, 2005. DOI: 10.1016/j.fcr.2005.01.017.

SOUZA, G.S. de. Controle de tráfego agrícola e seus efeitos nos atributos do solo e na cultura da cana-de-açúcar. 2012. 98p. Tese (Doutorado em Engenharia Agrícola) - Universidade Estadual de Campinas, Campinas.

SOUZA, G.S. de; SOUZA, Z.M. de; COOPER, M.; TORMENA, C.A. Controlled traffic and soil physical quality of an Oxisol under sugarcane cultivation. Scientia Agricola, v.72, p.270-277, 2015. DOI: 10.1590/0103-9016-2014-0078.

STOLF, R. Teoria e teste experimental de fórmulas de transformação dos dados de penetrômetro de impacto em resistência de solo. Revista Brasileira de Ciência do Solo, v.15, p.229-235, 1991.

SUZUKI, L.E.A.S.; REICHERT, J.M.; REINERT, D.J; LIMA, C.L.R. de. Grau de compactação, propriedades físicas e rendimento de culturas em Latossolo e Argissolo. Pesquisa Agropecuária Brasileira, v.42, p.1159-1167, 2007. DOI: 10.1590/S0100204X2007000800013.

TAVARES FILHO, J.; BARBOSA, G.M.C.; GUIMARÃES, M.F.; FONSECA, I.C.B. Resistência do solo à penetração e desenvolvimento do sistema radicular do milho (Zea mays) sob diferentes sistemas de manejo em um Latossolo Roxo. Revista Brasileira de Ciência do Solo, v.25, p.725-730, 2001. DOI: 10.1590/S0100-06832001000300022.

TIM CHAMEN, W.C.; MOXEY, A.P.; TOWERS, W.; BALANA, B.; HALLETT, P.D. Mitigating arable soil compaction: a review and analysis of available cost and benefit data. Soil and Tillage Research, v.146, p.10-25, 2015. DOI: 10.1016/j.still.2014.09.011.

UNGER, P.W.; KASPAR, T.C. Soil compaction and root growth: a review. Agronomy Journal, v.86, p.759-766, 1994. DOI: 10.2134/ agronj1994.00021962008600050004x.

VAN LIER, Q. de J.; GUBIANI, P.I. Beyond the "Least Limiting Water Range": rethinking soil physics research in Brazil. Revista Brasileira de Ciência do Solo, v.39, p.925-939, 2015. DOI: 10.1590/01000683rbcs20140596.

VASCONCELOS, A.C.M. de. Dinâmica do desenvolvimento radicular da cana de açúcar. In: VASCONCELOS, A.C.M. 
de; MIRANDA, L.D. Dinâmica do desenvolvimento radicular da cana-de-açúcar e implicações no controle de nematóides. 2.ed. rev. e ampl. Campinas: Adonis, 2011. p. 12-43.
VENN, B.W.; BOONE, F.R. The influence of mechanical resistance and soil water on the growth of seminal roots of maize. Soil and Tillage Research, v.16, p.219-226, 1990. DOI: 10.1016/01671987(90)90031-8.

Recebido em 28 de agosto de 2015 e aprovado em 14 de dezembro de 2015 